\title{
Effect of Imidapril, an Angiotensin-converting Enzyme Inhibitor, on Fructose-induced Insulin Resistance in Rats
}

\author{
TSUNEYUKI ODA, MASANOBU HIRATA, YOSHIHARU OSHIDA, YAN-QING HAN, KEIICHI KOSHINAKA \\ AND YUZO SATO
}

Research Center of Health, Physical Fitness and Sports, Nagoya University, Nagoya 464-8601, Japan

\begin{abstract}
The effect of imidapril, an angiotensin-converting enzyme (ACE) inhibitor, on insulin resistance was studied in high-fructose-fed rats. A sequential hyperinsulinemic euglycemic clamp procedure (insulin infusion rates: 3 and $30 \mathrm{mU} /$ $\mathrm{kg} \mathrm{BW} / \mathrm{min}$ ) was employed in 15 high-fructose-fed rats and 10 normal chow-fed rats under the awake condition. Five of the high-fructose-fed and five of the normal chow-fed rats, respectively, were continuously given imidapril (5 mg/kg BW/ min) or saline during the two-step euglycemic clamp study. Furthermore, both imidapril and L-NMMA were infused in another 5 high-fructose-fed rats during the low-dose insulin clamp. Glucose infusion rate (GIR) was regarded as an index of the whole-body insulin action. In the low-dose insulin infusion, the high-fructose feeding resulted in a marked decrease in GIR $(p<0.05)$. Imidapril infusion significantly raised the GIRs in the high-fructose-fed rats $(p<0.05)$. There was no significant difference in GIRs between the chow-fed rats and the imidapril-infused rats with high-fructose diet. In the high-fructose-fed rats, L-NMMA abolished the increase in GIR induced by imidapril $(p<0.05)$. Imidapril did not significantly change the GIRs in the chow-fed rats. In the high-dose insulin infusion, no significant difference in GIR was found among the chow-fed rats, the chow-fed rats given imidapril, the high-fructose-fed rats, and the high-fructose-fed rats given imidapril. These results suggest that, in insulin-resistant rats induced by the high-fructose feeding, an ACE inhibitor, such as imidapril, can improve the whole-body insulin-mediated glucose disposal and that this effect of imidapril is essentially linked to increased activation of NO-pathway.
\end{abstract}

Key words: Insulin sensitivity, ACE inhibitor, Nitric oxide

(Endocrine Journal 51: 69-74, 2004)

INSULIN resistance plays an important role in the incidence and progression of type 2 diabetes [1]. Insulin resistance is exacerbated by modern westernized lifestyles such as overeating, sedentary state and stressful daily life [2]. Hypertension is present at the time of diagnosis of diabetes in about one third of the patients with type 2 diabetes [3]. Imidapril, a non-sulfhydrylcontaining ACE inhibitor, leads to smooth-muscle relaxation and a reduction of vascular resistance, and improves high blood pressure. It has been used clinically in the treatment of hypertension, chronic congestive heart failure, acute myocardial infarction, and diabetic

Received: February 13, 2003

Accepted: October 20, 2003

Correspondence to: Yuzo SATO, M.D., Ph.D., Research Center of Health, Physical Fitness and Sports, Nagoya University, Furocho, Chikusa-ku, Nagoya 464-8601, Japan nephropathy. The effect of an ACE inhibitor on neointima formation was blocked by a NO synthase inhibitor [4]. Urinary excretion of nitrite/nitrate in response to L-arginine was increased by imidapril, but remained unchanged by calcium antagonist [5]. It has been, therefore, suggested that ACE inhibitors are associated with an increase in nitric oxide (NO) concentrations.

Other ACE inhibitors increase insulin sensitivity in animal models of insulin resistance $[6,7]$ and may have similar effects in insulin resistant patients [8]. Captopril, an other ACE inhibitor, increased the amount of glucose needed to maintain euglycemia during an euglycaemic hyperinsulinemic clamp [9]. Kinins contribute to the improvement of insulin sensitivity during treatment with ACE inhibitor, enalapril, but angiotensin II receptor antagonists do not affect the glucose requirement for the euglycemic clamp procedure [10]. The dual ACE/neutral endopeptidase inhibition by 
mixanpril increase insulin sensitivity to a greater extent than does either single peptidase inhibition [11]. The improvement of insulin sensitivity by bradykinin is likely mediated through kinin B2 receptors activation, and then by an increase in NO production and action in isolated epitrochlearis muscles from obese Zucker rats [12].

On the other hand, sodium nitroprusside (SNP), an NO donor, improved insulin resistance induced by high-fructose-fed rats during hyperinsulinemic euglycemic clamp [13]. Moreover, Carvalho et al. [14] demonstrated that captopril or bradykinin enhanced the insulin-induced increase in insulin receptor phosphorylation, insulin receptor substrate-1 (IRS-1) phosphorylation, and phosphatidylinositol 3-kinase (PI 3-kinase) association with IRS-1 in normal rats. Nawano et al. [15] also found the same results in imidapril treated Zucker fatty rats. Miyata et al. [16] showed that bradykinin administration could enhance insulin signaling, glucose transporter isoform (GLUT)4 translocation, and insulin-stimulated glucose uptake in canine skeletal muscle. Increased bradykinin circulating level, induced by treatment with an ACE-inhibitor, inhibits dephosphorylation of the insulin receptor, which results in enhancement of insulin receptor phosphorylation and subsequently PI 3-kinase activation [17]. It is likely, therefore, that bradykinin can enhance insulin-stimulated glucose transport activity in insulinresistant skeletal muscle by interacting with these steps in insulin signaling, which are essential for the activation of insulin-mediated GLUT-4 translocation and glucose transport. These findings suggest that imidapril improves insulin resistance induced by high-fructose feeding via NO. We therefore studied the acute effect of imidapril on whole-body glucose disposal in insulin-resistant rats induced by high-fructose feeding, using a two-step hyperinsulinemic euglycemic clamp procedure. We assessed the role of NO pathway in the effect of imidapril by using the NO-synthase inhibitor, N-monomethyl-L-arginine (L-NMMA).

\section{Materials and Methods}

\section{Animals}

Male Wistar rats weighing between 190-230 g were used for the study. Animals were housed in individual cages in a room maintained at $22-23^{\circ} \mathrm{C}$ with $12 \mathrm{~h}$ light/dark cycle and had free access to food and water. All procedures were in accordance with the Guide for the Use of Laboratory Animals of Nagoya University.

After a 1 wk acclimation period, rats were randomly divided into two groups: a standard chow-diet $(n=10$, powdered rodent MF, Oriental Yeast Co., Chiba, Japan) and a high-fructose diet $(n=15)$. The caloric composition of the chow-diet was 59\% vegetable starch, $29 \%$ protein, and $12 \%$ fat. The corresponding composition for the high-fructose diet was $60 \%$ fructose, $28 \%$ protein, $12 \%$ fat. The high-fructose diet was freshly made every 3 days and was stored at $4{ }^{\circ} \mathrm{C}$. The body weights of the animals were measured daily. After 2 wk on these conditions rats were anesthetized with an intraperitoneal injection of $50 \mathrm{mg} / \mathrm{kg}$ BW sodium pentobarbital. Thereafter, a middle ventral incision was made in the neck, and the right jugular vein and left carotid artery were cannulated with silascon SH tubing (No. 00, Kameka Medix, Osaka, Japan). The catheters were tunneled subcutaneously to the back of the neck and flushed with $300 \mathrm{ml}$ of saline containing heparin $(40 \mathrm{U} / \mathrm{ml})$ and $500 \mu \mathrm{l}$ sodium penicillin $\mathrm{G}(10,000 \mathrm{U} /$ $\mathrm{ml})$. They were then filled with a viscous solution of $50 \%$ polyvinylpyrrolidone (PVP-30, Sigma, St. Louis, $\mathrm{MO}$, USA) and capped with a piece of polyethylene tubing melted and sealed at one end. After surgery each rat was kept at the same conditions as the preoperative states. Rats recovered food intake 1-2 days after surgery.

\section{Euglycemic clamp procedure}

One week after surgery, a two-step hyperinsulinemic euglycemic clamp procedure was performed on each rat after an overnight fast to assess whole body insulin action $[13,19]$. The rat was placed in a restraining cage to which it was accustomed, and extension tubing was attached to the jugular catheter by an adapter for the continuous infusion of insulin (Actrapid MC Novo Nordisk, Denmark) and glucose. The carotid catheter was used for blood sampling. A primed infusion was delivered at a rate of $3 \mathrm{mU} / \mathrm{kg} \mathrm{BW} / \mathrm{min}$ (low-dose) for $90 \mathrm{~min}$ and then at an increased rate of $30 \mathrm{mU} / \mathrm{kg} \mathrm{BW} /$ min (maximal stimulation, high-dose) for an additional $90 \mathrm{~min}$. Five of the high-fructose-fed and 5 of the normal chow-fed rats, respectively, were continuously given imidapril ( $5 \mathrm{mg} / \mathrm{kg} \mathrm{BW} / \mathrm{min})$, ACE inhibitor, during the two-step euglycemic clamp study. Furthermore, both imidapril and L-NMMA $(1 \mathrm{mg} / \mathrm{kg} / \mathrm{min})$ were in- 
fused in five of the high-fructose-fed rats during the low-dose insulin clamp. The dosage for L-NMMA were expected to be sufficient to effect NO-synthase inhibition [18]. Saline was given to the other rats of the two groups instead of imidapril in the control study. The blood glucose concentration was kept constant at the basal level with a variable infusion of $20 \%(\mathrm{w} / \mathrm{v})$ glucose solution, based on the blood glucose concentration measured every $10 \mathrm{~min}[13,19]$. Additional blood samples were collected just before insulin infusion and at $90 \mathrm{~min}$ and $180 \mathrm{~min}$ after starting insulin infusion for the determination of plasma insulin concentrations. The glucose infusion rate (GIR) in $\mathrm{mg} / \mathrm{kg} \mathrm{BW} / \mathrm{min}$ was calculated every $10 \mathrm{~min}$ during the clamp study. The mean GIR values from 60 to $90 \mathrm{~min}$ and 150 to $180 \mathrm{~min}$ for the two-step sequential euglycemic clamp procedure were regarded as an index of whole body insulin action since a plateau in the glucose infusion rate was achieved during these times.

\section{Analytical methods}

Blood glucose concentration was determined with a YSI 2300 STAT glucose analyzer (Yellow Springs Instrument Co., OH, USA ). Plasma insulin was assayed with a radioimmunological assay kit (Phadeseph Insulin RIA, Pharmacia AB, Stockholm, Sweden). Samples were immediately separated into plasma and cell portions in a centrifuge at $4{ }^{\circ} \mathrm{C}$ and stored at $-70^{\circ} \mathrm{C}$ until analysis.

All values are presented as means \pm SEM. Statistical analysis was performed using analysis of variance followed by Fisher's PLSD test. Values of $p<0.05$ were considered significant.

\section{Results}

\section{Body weight, blood glucose, plasma insulin}

Body weight, blood glucose and plasma insulin levels before and after the clamp procedure are shown in Table 1. These values before and after the clamp were not significantly different among the five groups. During the clamp studies, the glucose concentrations in all rats were kept at the basal concentrations.

\section{Glucose infusion rate (GIR)}

The average GIRs for the last $30 \mathrm{~min}$ during the low-dose and the high-dose insulin infusion rates are shown in Figure 1 and 2. At the insulin infusion rate of $3.0 \mathrm{mU} / \mathrm{kg} \mathrm{BW} / \mathrm{min}$ (low-dose, Fig. 1), the highfructose feeding resulted in a marked decrease in GIR, compared with the chow-fed rats $(4.01 \pm 0.46$ vs $8.92 \pm 0.72 \mathrm{mg} / \mathrm{kg} \mathrm{BW} / \mathrm{min}, \mathrm{p}<0.05)$. Imidapril infusion significantly raised the GIRs in the high-fructosefed rats $(9.20 \pm 0.72 \mathrm{mg} / \mathrm{kg} \mathrm{BW} / \mathrm{min}, \mathrm{p}<0.05)$. There was no significant difference in GIRs between the chow-fed rats and the imidapril infused rats with highfructose diet. In the high-fructose-fed rats, L-NMMA abolished the increase in GIR induced by imidapril $(6.70 \pm 0.94 \mathrm{mg} / \mathrm{kg} \mathrm{BW} / \mathrm{min}, \mathrm{p}<0.05)$. The chow-fed rats given imidapril tended to increase the GIRs, but not significantly so, compared with the chow-fed rats. In the high-dose insulin infusion, no significant difference in GIR was found among the chow-fed rats, the chow-fed rats given imidapril, the high-fructose-fed rats, and the high-fructose-fed rats given imidapril (Fig. 2).

Table 1. Body weight, blood glucose, and plasma insulin levels before and during the sequential euglycemic clamp procedure at lowdose and high-dose insulin infusions

\begin{tabular}{|c|c|c|c|c|c|c|c|}
\hline & \multirow{2}{*}{ Body wt (g) } & \multicolumn{3}{|c|}{ Glucose (mg/dl) } & \multicolumn{3}{|c|}{ Insulin $(\mu \mathrm{U} / \mathrm{ml})$} \\
\hline & & Basal & L-dose & H-dose & Basal & L-dose & H-dose \\
\hline \multicolumn{8}{|l|}{ Chow-fed } \\
\hline Saline (5) & $269 \pm 1$ & $75 \pm 2$ & $79 \pm 1$ & $73 \pm 1$ & $5 \pm 1$ & $20 \pm 3$ & $608 \pm 59$ \\
\hline Imidapril (5) & $265 \pm 5$ & $78 \pm 2$ & $73 \pm 2$ & $73 \pm 3$ & $5 \pm 1$ & $30 \pm 2$ & $646 \pm 75$ \\
\hline \multicolumn{8}{|l|}{ High-fructose-fed } \\
\hline Saline (5) & $266 \pm 3$ & $78 \pm 5$ & $77 \pm 3$ & $74 \pm 2$ & $9 \pm 2$ & $34 \pm 3$ & $623 \pm 66$ \\
\hline Imidapril (5) & $259 \pm 7$ & $75 \pm 3$ & $76 \pm 2$ & $76 \pm 2$ & $6 \pm 0$ & $25 \pm 7$ & $613 \pm 108$ \\
\hline Imidapril + LNMMA (5) & $268 \pm 5$ & $74 \pm 3$ & $74 \pm 2$ & - & $7 \pm 1$ & $27 \pm 4$ & - \\
\hline
\end{tabular}

Values are means $\pm \mathrm{SEM}$. The number of rats is shown in parentheses. 


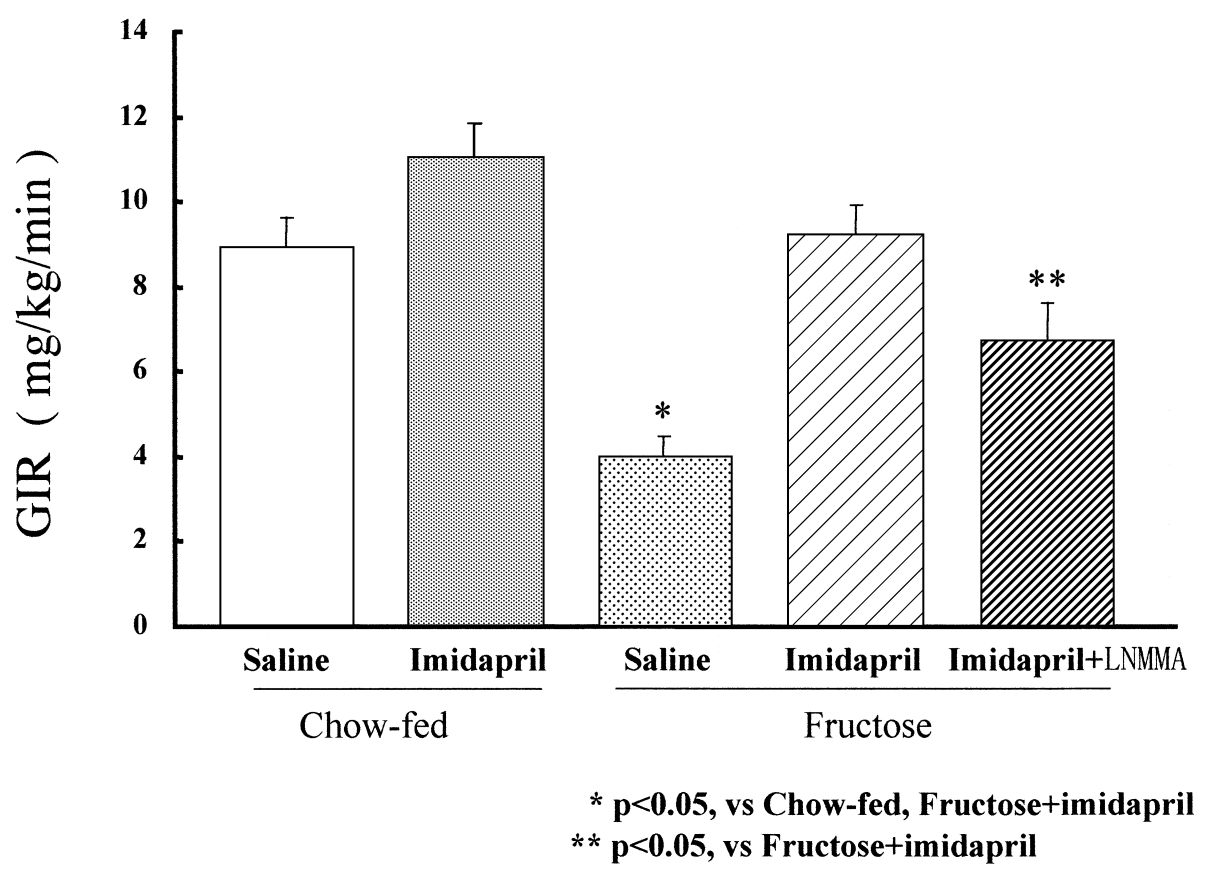

Fig. 1. Glucose infusion rate (GIR) for euglycemic clamp procedure at low-dose ( $3 \mathrm{mU} / \mathrm{kg} \mathrm{BW} / \mathrm{min})$.

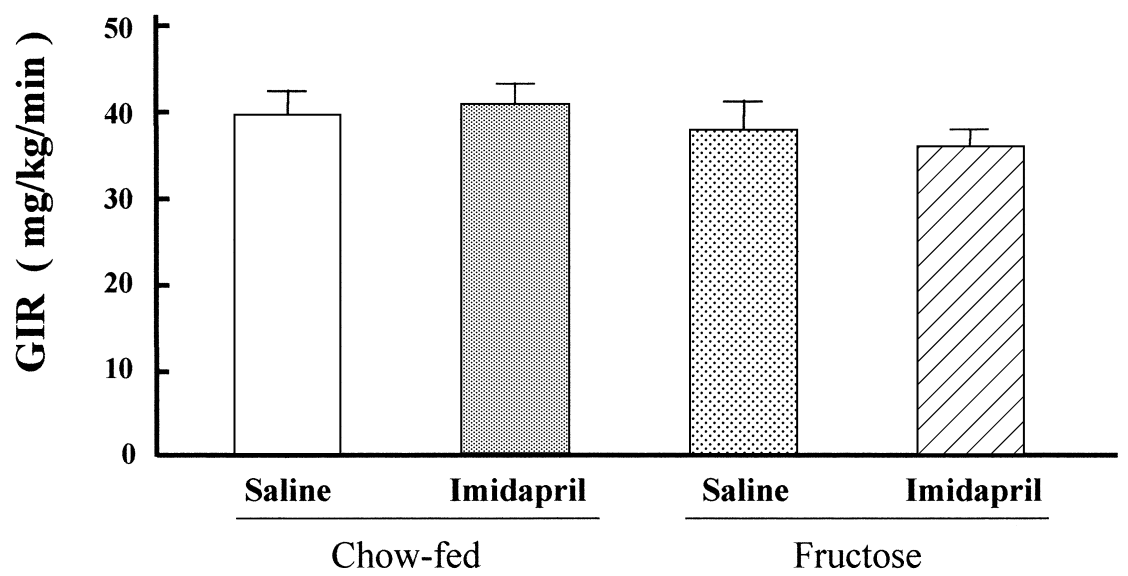

Fig. 2. Glucose infusion rate (GIR) for euglycemic clamp procedure at high-dose $(30 \mathrm{mU} / \mathrm{kg} \mathrm{BW} / \mathrm{min})$.

\section{Discussion}

This study was designed to investigate the effect of the ACE inhibitor, imidapril, on the whole-body insulin action in high-fructose fed rats. It has been shown that muscle glucose transport can be stimulated by $\mathrm{NO}$, and that NO synthase in its neural and endothelial isoforms are expressed in skeletal muscle [20]. Moreover, imidapril is reported to enhance the concentration of nitrite/nitrate in coronary artery [4]. Therefore, we examined the influence of L-NMMA, an inhibitor of NO synthase, on the increased whole-body insulin sensitivity induced by imidapril under the same plasma insulin levels during euglycemic clamp. The result indicated that one possible mechanism for the improvement on insulin sensitivity is due to an NO-mediated pathway. This finding was also observed in previous reports using insulin-resistant rats [11, 12]. Although it is also observed in isolated muscle tissue under in vitro conditions [12], imidapril can improve insulin resistance not only by increasing blood flow in tissues by normalizing vascular resistance, but also by acting 
directly on the insulin signaling pathway [5].

Henriksen et al. showed that endogenous bradykinin, resulting from the ACE inhibition, can enhance insulin action on glucose uptake via an increased activation of the bradykinin $\mathrm{B} 2$ receptors and via an increase in NO production [11, 12]. The acute administration of captopril to the insulin-resistant aged rats augmented the early steps in the insulin signal cascade in skeletal muscle, such as insulin-induced phosphorylation of insulin receptors, IRS-1 and PI3kinase [14]. Imidapril also improved insulin sensitivity by acting directly on the insulin signaling pathway, IRS-1 and PI3-kinase [15]. Bradykinin administration can enhance glucose transporter isoform (GLUT-4) translocation and insulin-stimulated glucose uptake in canine skeletal muscle [17]. But it is unknown how the bradykinin-NO pathway promotes insulinstimulated GLUT-4 translocation. Recently, we have shown that NO synthase protein content in muscle is not affected by fructose-induced insulin resistance and pioglitazone [21]. It is possible that the insulin sensitizing action of imidapril is associated with NOS activity and/or nitric oxide acceptability rather than the protein content. Moreover, the effect of L-NMMA on GIR in fructose-fed rats infused imidapril was rather small (40\% reduction), suggesting that other factors contribute to improvement of insulin action by imidapril. Similar levels of maximum insulin-stimulated GIRs was also found among the 4 groups in the present study. Our previous study showed increased GIRs in both submaximal and maximal insulin stimulations $[13,21]$. The difference may be due to the different body weights of rats. The body weights of rats were identical in the present study, but they were greater in the fructose-fed rats than in the normal chow-fed rats. Since we also did not measure blood pressure or heart rate during the clamp study, further studies are necessary.

Based upon the present results, it is suggested that in insulin-resistant rats induced by the high-fructose feeding, the ACE inhibitor, imidapril, improves the whole-body insulin-mediated glucose disposal and that this effect of imidapril is in part linked to increased activation of the NO-pathway.

\section{References}

1. Olefsky JM, Kolterman OG (1981) Mechanisms of insulin resistance in obesity and non-insulin-dependent (type II) diabetes. Am J Med 70: 151-168.

2. Goodyear L, Smith RJ (1994) Exercise and diabetes. In: Kahn CR, Weir GC (eds) Joslin's Diabetes Mellitus, Philadelphia: Lea Febiger. 451-459.

3. Clark CM Jr, Lee DA (1995) Prevention and treatment of the complications of diabetes mellitus. $N$ Engl J Med 332: 1210-1217.

4. Farhy RD, Carretero OA, Ho KL, Scicli AG (1993) Role of kinins and nitric oxide in the effects of angiotensin converting enzyme inhibitors on neointima formation. Circ Res 72: 1202-1210.

5. Higashi Y, Oshima T, Sasaki S, Nakano K, Kambe M, Matsuura H, Kajiyama G (1998) Angiotensin-converting enzyme inhibition, but not calcium antagonism, improves a response of the renal vasculature to L-arginine in patients with essential hypertension. Hypertension 32: $16-24$

6. Henriksen EJ, Jacob S, Tritscher HJ, Augustin HJ, Dietze GJ (1996) Glucose transport activity in insulinresistant rat muscle. Effect of angiotensin-converting enzyme inhibitors and bradykinin antagonism. Diabetes 45: S125-S128.

7. Nakagawa $H$, Daihara $M$, Tamakawa $H$, Nozue $T$ (1999) Effect of quinapril and losartan on insulin sensi- tivity in genetic hypertensive rats with different metabolic abnormalities. J Cardiovasc Pharmacol 34: 2833.

8. Uehara M, Kishikawa H, Isami S, Kisanuki K, Ohkubo Y, Miyamura Y, Miyata T, Yano T, Shichiri M (1994) Effect of insulin sensitivity of angiotensin-converting enzyme inhibitors with or without a sulphydryl group: bradykinin may improve insulin resistance in dogs and humans. Diabetologia 37: 300-307.

9. Damas J, Bourdon V, Lefebvre PJ (1999) Insulin sensitivity, clearance and release in kininogen-deficient rats. Exp Physiol 84: 549-557.

10. Tomiyama $\mathrm{H}$, Kushiro $\mathrm{T}$, Abeta $\mathrm{H}$, Ishii $\mathrm{T}$, Takahashi A, Furukawa L, Asagami T, Hino T, Saito F, Otsuka Y, Kurumatani H, Kobayashi F, Kanmatsuse K, Kajiwara N (1994) Kinins contribute to the improvement of insulin sensitivity during treatment with angiotensinconverting enzyme inhibitor. Hypertension 23: 450-455.

11. Arbin V, Claperon N, Fournie-Zaluski M-C, Roques BP, Peyroux J (2001) Acute effect of the dual angiotensin-converting enzyme and neutral endopeptidase 24-11 inhibitor mixanpril on insulin sensitivity in obese Zucker rat. Br J Pharmacol 133: 495-502.

12. Henriksen EJ, Jacob S, Kinnick TR, Youngblood EB, Schmit MB, Dietze GJ (1999) ACE inhibition and glucose transport in insulin-resistance muscle. Role of 
bradykinin and nitric oxide. Am J Physiol 277: R332R336.

13. Oshida Y, Tachi Y, Morishita Y, Kitakoshi K, Fuku N, Han Y-Q, Ohsawa I, Sato Y (2000) Nitric oxide decreases insulin resistance induced by high-fructose feeding. Horm Metab Res 32: 339-342.

14. Carvalho CRO, Thirone ACP, Gontijo JAR, Velloso LA, Saad MJA (1997) Effect of captopril, losartan, and bradykinin on early steps of insulin action. Diabetes 46: 1950-1957.

15. Nawano M, Anai M, Funaki M, Kobayashi H, Kanda A, Fukushima Y, Inukai K, Ogihara T, Sakoda H, Onishi Y, Kikuchi M, Yazaki Y, Oka Y, Asano T (1999) Imidapril, an angiotensin-converting enzyme inhibitor, improves insulin sensitivity by enhancing signal transduction via insulin receptor substrate proteins and improving vascular resistance in the Zucker fatty rat. Metabolism 48: 1248-1255.

16. Miyata $\mathrm{T}$, Taguchi $\mathrm{T}$, Uehara M, Isami S, Kishikawa H, Kaneko K, Araki E, Shichiri M (1998) Bradykinin potentiates insulin-stimulated glucose uptake and enhances insulin signal through the bradykinin B2 receptor in dogs skeletal muscle and rat L6 myoblasts. Eur J Endocrinol 138: 344-352.

17. Henriksen EJ, Jacob S (1995) Effects of captopril on glucose transport activity in skeletal muscle of obese Zucker rats. Metabolism 44: 267-272.

18. Gardiner SM, Kemp PA, March JE, Bennett T (1995) Cardiac and regional haemodynamics, inducible nitric oxide synthase (NOS) activity, and the effects of NOS inhibitors in conscious, endotoxaemic rats. $\mathrm{Br} \mathrm{J}$ Pharm 116: 2005-2016.

19. Han Y-Q, Oshida Y, Li L, Koshinaka K, Fuku N, Yamanouchi K, Sato Y (2001) Effect of voluntary wheel-running on insulin sensitivity and responsiveness in high-fat-fed rats. Endocri J 48: 551-555.

20. Roy D, Perreault M, Marette A (1998) Insulin stimulation of glucose uptake in skeletal muscles and adipose tissues in vivo is NO dependent. Am J Physiol 274: E692-E699.

21. Koshinaka K, Oshida Y, Han Y-Q, Ohsawa I, Sato Y (2004) The effect of nitric oxide synthase inhibitor on improved insulin action by pioglitazone in highfructose-fed rats. Metabolism 53: 22-27. 